\title{
ENTREVISTA A FRANZ HINKELAMMERT
}

Por Juan José Bautista Segales

Moravia, Costa Rica, Octubre de 2017

J. J. Bautista: $\quad$ Maestro, estamos en el 2017, hace 150 años salió la primera edición del I Tomo de El Capital, de Karl Marx, el 14 de septiembre de 1867 .

F. Hinkelammert: En el fondo no era el I Tomo, era El Capital, no había ni Tomo II ni III, ni estaba a la vista, era El Capital, y Engels lo transformó en el I Tomo. Eso está bien, pero para Marx El Capital era ese I Tomo .

J. J. Bautista: Y el próximo año celebraremos el doscientos aniversario del nacimiento de Marx, en el 2018.

F. Hinkelammert: Hay que distinguir entre el joven Marx, y el maduro. El joven no se sabe hasta cuándo dura, pero con 30 años era todavía bastante joven, después ya madura. En 1844 ya tenía grandes obras, solo algunas se publicaron, pero ese es el joven Marx, 26 años tenía. Y de ahí tomó Althusser, etcétera. Y Althusser decía: Después de esto, todo es marxista. De hecho, aunque no lo diga directamente, lo que dice es: "Lo que coincide con mis pensamientos es marxista y lo que no, pues no es marxista".

J. J. Bautista: Entonces, estas fechas están coincidiendo con lo que se llama la crisis no solamente del capitalismo, sino también de la modernidad. Ahora, lo que estamos viendo son ya los efectos de las crisis climáticas, estos sismos que acaban de acontecer, por ejemplo, en México, y ahora esto de los huracanes. Y todo este contexto, empezando con las crisis económicas, ha planteado la posibilidad, no solamente de revisar los presupuestos sobre los cuales se ha seguido desarrollando 
el capitalismo y la Modernidad, sino el modo como podemos seguir pensando la crítica. Entonces, en el siglo XX se ha trabajado un tipo de pensamiento crítico y, supuestamente, estaba aclarado, había servido, funcionado. Y, en parte, estaba superado. Pero ahora se está viendo que no había sido así, y por eso la vuelta al gran clásico, en este caso al gran Marx. Y, al mismo tiempo, el retorno a las grandes preguntas, que supuestamente estaban aclaradas y superadas, pero que ahora hay que volver a hacerlas. Hemos elaborado algunas preguntas y quisiéramos seguir este orden. Supuestamente, desde la perspectiva del materialismo dialéctico, se había aclarado muy bien qué significaba materialismo en Marx, y ya sabemos que no es así. Entonces, en el contexto de toda la reflexion que usted ha hecho en torno a la obra de Marx, ¿cómo usted definiría, explicaría, qué es aquello que Marx entendía por materialismo?

F. Hinkelammert: En nuestro lenguaje, él entiende por materialismo varias cosas, pero tienen muy poco que ver realmente con la visión de Marx. Hegel, para él, no es un materialista, es un idealista, y decía: "Hegel está de cabeza, hay que ponerlo de pie”. Ese es el materialismo de Marx, poner a la gente que estaba de cabeza, con su idealismo, de pie. Y ponerla de pie significa pensar todo a partir de la corporeidad, el ser humano, el mundo... Y esta corporeidad tiene alma y tiene espíritu, pero el espíritu es lo interior de la corporeidad, no es una sustancia aparte. Y yo creo que eso, en la palabra materialismo, hoy no se transmite. Yo creo que mucho de eso se transmitió en el siglo XIX, pero hoy no. Por ejemplo, los empresarios hacen plata, entonces se dice que son materialistas, ¡no son materialistas, son idealistas! Pero los llamamos materialistas. Y eso es un honor que no merecen, porque destruyen la materia, y la sustituyen por dinero, entonces, viven por dinero. Y el dinero es algo espiritual, no 
es material. El dinero... ni puedes verlo, en el sentido estricto. Si ves mis billetes eso no dice que sea dinero, puede ser una falsificación, entonces no es dinero. Lo que tú ves no es dinero, por eso lo puedes tener en una tarjeta, tú pagas y no hay dinero, no hace falta, o es dinero, pero el dinero no es algo que se tiene a la mano. De ahí que la problemática del espíritu y el cuerpo está en cuestión. Marx tiene esta tradición, de que el espíritu es lo que hace vivir el cuerpo, cuando el cuerpo vive, vive el espíritu, espiritualmente no puedes vivir si estás muerto, y eso es, en el fondo, una larga tradición, sobre todo judía. A Pablo de Tarso le preguntaron: “Qué pasa después de morir? De ahí hasta la resurrección van a dormir, porque no se puede vivir si no hay cuerpo", eso es judío, de ahí tiene Marx eso. Y yo creo que hoy, en psicología, en muchas partes, se entiende eso en ese sentido, el hecho de que el cuerpo viva, eso es la vida. Y lo que distingue la vida de la muerte es el cuerpo, que es lo que muere o vive, pero no es una cosa aparte, no hay un alma. ¡Hasta en Pablo de Tarso! Entonces, ¿qué es? Una sombra. Los judíos también decían que es estar en una sombra. Pero nunca existen realmente como alma, eso sería muy griego. Y viene con la agnosis al cristianismo. El cristianismo no conoce el alma; para Jesús el alma es la vida del cuerpo. El cuerpo, cuando vive, se puede decir que vive y también que tiene alma. Es lo mismo, casi lo mismo, y eso, la palabra materialismo tendría que transmitirlo, pero no lo hace, y no tenemos otra palabra que lo transmita realmente. Yo muchas veces prefiero hablar de la corporeidad, pero de la corporeidad viva. Pero el alma, como sustancia, para Marx no es eso. Frente a la dialéctica de Hegel, que es una dialéctica del espíritu, él quiere una dialéctica a partir de lo corporal, lo corporal vivo, no del cuerpo muerto; tiene su dialéctica. 
J. J. Bautista: Claro, entonces, lo que podríamos decir sería lo siguiente: la especificidad del pensamiento de Marx consiste en que la racionalidad material es una racionalidad que piensa desde la corporalidad viviente, tomando en cuenta la corporalidad viva. En cambio, la racionalidad formal o idealista, piensa sin corporalidad viviente, o sea, como si no tuviésemos cuerpo.

F. Hinkelammert: Exacto, sí.

J. J. Bautista: Como si eso no fuese problema.

F. Hinkelammert: Sí, entonces se puede reducir a racionalidad medio-fin. Pero el medio-fin es una parte, no más, de la racionalidad, de una racionalidad vida-muerte. En el vivir o morir está la clave de la racionalidad. Si tú atraviesas una calle donde hay mucho tráfico, sabes que el camino más recto es directo, entonces, si la racionalidad medio-fin es marchar y lo haces, estás muerto después de dos pasos. Tienes que poner en segundo lugar el medio-fin, porque se trata de vida o muerte. Si tú puedes vivir con eso, entonces es racional. Nuestra racionalidad excluye eso. Si está muerto otro no importa, no tengo nada más que la relación medio-fin. Es decir, el problema de la bomba atómica es poder hacerla, pero el verdadero problema es un problema vida-muerte, no aplicarla. Y eso es la verdadera racionalidad que está por encima de la racionalidad medio-fin. Eso se deja de lado, entonces tienes físicos que dicen: ¡la racionalidad!, pero es una racionalidad totalmente trunca, porque producen bombas atómicas, pero ellos no tienen ningún criterio que implique decidir usarla o no, y eso es lo decisivo. Entonces, este Trump la va a tirar, yo creo que él quiere eliminar toda Corea del Norte. La racionalidad es, entonces, tener la bomba atómica y usarla; que eso sea muerte no es parte del pensamiento humano racional. Eso ya es Max Weber, siempre dice que la cuestión vida-muerte no es de la ciencia. Por eso Marx está frente 
J. J. Bautista: Entonces, lo que podríamos decir sería que lo que hoy es la racionalidad formal es idealista, y lo es porque hace abstracción de la materialidad de la vida.

F. Hinkelammert: Y la materialidad de la vida significa una vida, un cuerpo, frente a la cuestión vida-muerte, un cuerpo que asegure vivir con la vida y no para la muerte. Y ahí, entonces, está el asunto. La racionalidad formal, en sí, es irracional por esta razón. Entonces tienes que buscar cuál es él criterio sobre la irracionalidad de esta racionalidad formal. Eso es la razón, ese criterio. Si tomas a Max Weber, esas son decisiones emocionales, son emociones, eso no es racional. Si tú sobrevives o no, esa es cuestión de emociones, de racionalidad no, de racionalidad sería si te resulta construir la bomba atómica. Y de ahí que se haga tan difícil hablar de materialismo, de idealismo, cuando nuestro mundo es terriblemente idealista, por todos lados, pero lo real es la vida-muerte. Y no se lo toma como objeto de la razón, porque ahí "no opera" la racionalidad, operan las emociones.

J. J. Bautista: Entonces, a partir de ello, ¿podríamos decir, siguiendo el orden de las preguntas, que la especificidad de la dialéctica de Marx, como dialéctica materialista, sería la tematización de la contradicción vida-muerte?

F. Hinkelammert: Claro, y entonces, en la hegeliana tú tienes una cosa espiritual. Vida-muerte no entra en la reflexión y, al final, es el espíritu absoluto. Marx tiene otro final, que no es el espíritu absoluto, es lo que, en 1844, formula como comunismo, que es una vida lograda. Claro, después hay que ver cómo se hace para que se dé esa vida lograda, pero es una humanidad que vive una vida lograda. Esto sustituye al espíritu absoluto de Hegel, y esto solamente se puede discutir sobre la corporeidad del ser humano, 
la vida-muerte del ser humano. Y ahí aparece la otra dialéctica, y es una dialéctica, ahora, en relación con la idea, es también una idea, pero no es idealismo, la idea de una vida lograda, la vida lograda como comunismo. Descubres que, en el fondo, cada cultura tiene algún concepto de vida lograda, y no de espíritu absoluto, ninguna cultura se rige por espíritu absoluto, ni la de Hegel. Se trata de la vida lograda, y eso lo introduce Marx frente a Hegel. Eso ha producido también muchos malos entendidos, pero ese el problema, la vida lograda es lo que es lo racional, no es lo emocional. Pero lo que vamos a ver ahora es la racionalidad medio-fin. Es la razón que responde a la racionalidad de la relación medio-fin. En el lenguaje popular, la irracionalidad de la racionalidad medio-fin está en este dicho famoso: No debes cortar la rama del árbol sobre el cual estás sentado. ¿Eso es una racionalidad o no? Hay libros que hablan de racionalidad, de mil páginas, pero ni una sola vez se menciona eso, ¡no hay que cortar la rama del árbol sobre la cual tú estás sentado! Y si lo haces, tú eres el tipo más irracional, aunque hayas cortado muy bien, muy rápido, o aunque seas el primero que llega a cortar la rama, tú caes en la total irracionalidad. No tenemos presente eso; pero, en el lenguaje popular, en todas partes está presente, cualquier campesino te va a decir eso. Pero Max Weber no, los campesinos sí. Dicen que lo dijo Shakespeare, que cuando ya no se le ocurre nada, él se pone una ropa para ir a los bares de Londres y hablar con la gente, y después tiene buenas ideas, con Max Weber no le vendrían.

J. J. Bautista: En esta perspectiva, desde finales del siglo XIX, pero especialmente, en el siglo XX, que es cuando cobra relevancia la investigación científica, la ciencia moderna desarrolla su propia estructura cognitiva en términos de lógica, cosa que, después de Popper, se llama lógica de la 
investigación científica, y no llega a resultados, como a los que usted recuerda o hace alusión a partir de Marx, ¿qué tipo de estructura lógica habría desarrollado Marx, en el El Capital, para llegar a los resultados que ha llegado, pero a los que también usted está llegando?

F. Hinkelammert: Yo diría que es precisamente eso, la vida-muerte, calcular o someter todo cálculo al criterio de vida-muerte, y no a un criterio de verdad o no verdad. Vida-muerte, con un conocimiento de esto, se trata de puro vivir o me destruyo. Entonces, tú entiendes con el pensamiento del capitalismo que puedes vivir este siglo, todavía, pero el otro ya no. Tú desarrollas algo que, claro, es difícil llamarlo lógica, pero tiene una lógica. Y Marx, en El Capital, muy al final de la discusión sobre la plusvalía relativa, es decir, sobre el crecimiento de la economía, dice que el capitalismo no puede desarrollar las fuerzas productivas sin destruir tanto la naturaleza como al trabajador. Eso Marx lo publica en el 73. Y los marxistas... yo nunca he visto a alguien que haya citado eso, no. En el siglo XIX y siglo XX el marxismo no cita eso. Hoy, cuando tú vas a una discusión donde hay muchos marxistas, no se dan cuenta, ni saben que Marx ha dicho eso y, entonces, ¿cómo van a desarrollar la economía política de Marx? ¿Qué es de la plusvalía, plusvalía relativa? Y eso, si se lo dejas al capitalismo, el capitalismo lo destruye todo. Hasta el George Soros, que a veces es muy inteligente, decía: "El único enemigo del capitalismo, que puede destruirlo, es el capitalismo". Él percibe eso. Pero hablan tanto del mercado, como si el mercado hubiera hecho las cosas; es el instrumento con el cual se han producido grandes cosas, pero hoy se transforma en el instrumento para destruir todas las cosas que, por medio de él, se han podido hacer, que sin el mercado no se podrían haber hecho. Ahora se destruye todo eso por medio del mercado, el mercado 
da vuelta. Es como la gran superpernova, que cada vez luce más y un día se transforma en hoyo negro, y eso estamos viviendo, estamos en el punto en el que nuestra supernova se trasforma en hoyo negro, y la fuerza es la misma. Así es el mercado. Nunca ha habido una ideología tan pro-mercado como el neoliberalismo. Y hoy, que es visible la destrucción, esa es la ideología absolutamente dominante. Ahora, en Alemania, había elecciones: 6 partidos salieron con diputados, cinco de ellos son neoliberales, inclusive los verdes. Los verdes hoy se han ido a eso. Los verdes, los liberales, los demócratacristianos y los AFD. Lo único es la izquierda... ¡que tiene el 1\%! Es visible. Y neoliberalismo significa que el mercado es guiado por la mano invisible, es decir, hasta ponen un Dios, la mano invisible es la mano de Dios desde hace 2000. En la Tora empezaron a hablar de Dios en el cosmos como mano invisible. El gran físico inglés Isaac Newton decía que las estrellas son guiadas por la mano invisible. Entonces, viene Adam Smith, hace 200 años, un poco más, y dice que el mercado es guiado por la mano invisible. Nunca se ha tomado eso tan verbal como hoy, bueno, quizás en el capitalismo de Manchester. Pero no era teórico. Bueno, pero con esta brutalidad nunca, y ahora, sí. Y empieza a imponerse en 1980, sobre todo con Reagan. Empezó con el golpe militar chileno, después vino la Margaret Thatcher y después Reagan. Entonces, se hace eso sobre el mundo entero, la mano invisible. Eso sucede 8 años después de publicarse el Informe del Club de Roma, que había impactado a la gente, porque había dicho que tenemos poco tiempo, y que si no lo aprovechamos nos vamos todos al carajo. Pero, ¿cuál es la respuesta? 8 años después viene el mercado total, sin un límite, todo es mercado, y ahora el mercado nos destruye todo lo que por medio del mercado se ha hecho. Eso, me parece, es el problema. 
J. J. Bautista: Entonces, haciendo más o menos una síntesis de lo que está desarrollando usted, ahora podríamos decir que la lógica de Marx es dialéctica, no solo porque piensa a partir de la materialidad de la vida humana, sino que es una lógica dialéctica materialista porque piensa a partir de la contradicción vida-muerte y, a partir de ello, desarrolla una lógica de la vida.

F. Hinkelammert: Tiene como visión la vida lograda, en ese sentido sería una lógica de la vida.

J. J. Bautista: Qué parte explícitamente de esto que, como contradicción, vivimos siempre en el mundo de la vida cotidiana y, desde ahí, elabora un pensamiento pertinente como para poder entender esto que está sucediendo.

F. Hinkelammert: Sí, ahora se celebra mucho El Capital, pero los marxistas no saben qué hacer con El Capital. Donde se toma en serio es en los cursos en lectura del El Capital, el estudiantado, ese es el lugar y tiene su lado positivo, yo encuentro. Pero la teoría de Marx ha desaparecido, y es precisamente eso, que se trata de vida o muerte, y la opción por la vida es una opción en contra del capitalismo. Y, ¿qué marxista te va a decir eso? Bueno, hoy cambia, yo creo, hay figuras donde cambia, pero por un largo tiempo... claro, tú tienes a Walter Benjamin, que está en esta dirección, a Rosa Luxemburg, eso es cierto, pero estos no determinan. Con Althusser pasa exactamente lo contrario, él es mucho más leído que todos ellos juntos.

J. J. Bautista: Hasta ahora hay acólitos de Althusser.

F. Hinkelammert: Sí, y ahí hay una línea que, entonces, abandonó completamente el pensar. Asumieron el concepto de la racionalidad como medio-fin y, con eso, tú no puedes entender el pensamiento de Marx y, entonces, lo dejan de lado y estudian la economía neoclásica.

J. J. Bautista: Me gustaría que hiciéramos un pequeño giro hacia la perspectiva de una de las hipótesis fuertes que usted 
desarrolla en toda su obra, en el sentido de que el núcleo central de la obra de Marx sería una teoría del fetichismo, y que el contenido de ella sería el modo como el método de Marx arriba al final, deviene al final, como un momento de toma de conciencia, de madurez de todo su pensamiento. Es la crítica de los fetiches, que aparecen y que producen el capital y que, ahora, es la discusión contemporánea, de la que deviene esta tesis que está, en parte, de moda, pero no bien comprendida ni desarrollada, que Benjamín expresa al decir que el capitalismo es como una religión.

F. Hinkelammert: No es como una religión: ¡es una religión!

J. J. Bautista: Ahora hay una gran cantidad de evidencia al respecto. Pero al principio empieza así. Entonces, ¿como usted explicaría esto, que en Marx lo duro, lo fuerte, sería la teoría del fetichismo, y cómo es que, ahora, se podría seguir desarrollando?

F. Hinkelammert: El fetichismo es mirar la economía como si no fuera economía para la vida, mirarla desde el punto de vista de una economía para ganar dinero. Eso es el fetichismo, pero tiene ahí un centro que hoy cada vez se está elaborando, el mercado, con su capacidad única de autorregularse. Es la autorregulación del mercado y, entonces, este mismo mercado, al autorregularse, muestra que sigue a la mano invisible, y de la mano invisible no dicen mucho. ¿De quién es la mano invisible? Es la mano invisible del propio mercado que organiza todo, y ahí aparece una figura que, efectivamente, sustituye al Dios anterior, en gran parte, y lo penetra, penetra las religiones después. Pero es el mercado el gran milagro, por ahí hay un teórico... a veces pienso, ¿son teóricos estos? Dice que el mercado es una gran computadora pero, tan maravillosa, que es superior a cualquier computadora que un ser humano podría construir. Es tan gigantesca... y te soluciona todos los problemas, en el 
mercado y, por eso, la única opción racional es dejar funcionar el mercado, tiene que decidir el mercado. Por eso esta negativa neoliberal a reconocer que la crisis del medio ambiente hoy es un producto humano, porque entonces sería una falla del mercado, pero no puede ser una falla del mercado, por lo tanto, se repite que no se ha comprobado eso, que siempre ha habido cambios de temperatura, porque si tú lo vinculas al mercado, este, como Dios, calla. Entonces se equivocó, se está equivocando el mercado, y que la gente no pueda funcionar con el mercado ese es un problema de la gente. Tú puedes decir que la gente no sabe, que tiene que estudiar neoliberalismo para saber lo que es, pero a la naturaleza no le puedes decir eso. Entonces, tú tienes que negar que esto es un producto de la propia acción humana, que ciegamente se orienta por el mercado. El problema es, entonces, que se transforma el mercado en el problema, claro de una manera que Marx no previó. Marx creía que hay que abolir el mercado, porque el mercado hace este misterio, el mercado lo puede todo, y lo puede todo mucho mejor que cualquier ser humano, por lo tanto "tenemos que dejarlo funcionar". Pero ahora esto es cada vez menos y, entonces, tienen que mentir en cuanto a los orígenes de la crisis. Y lo hacen, por todos lados, y cada vez más. Por eso me sorprendí con esta señora Weider, de la AFD, de Alemania, un total pensamiento del mercado, todo lo tiene que soluciónar el mercado, al Estado lo necesitamos nada más que para la policía, el servicio secreto, militar y para aplicar el Código Civil. Eso, nada más. Y lo han logrado, eso es lo curioso. Eso se ha impuesto, por eso los partidos políticos... yo tomo el caso de Alemania, pero en Costa Rica es lo mismo, tú tienes de repente un grupo que no, pero Liberación, los libertarios ni hablar, otros, todos están pensando partir del mercado. Y tú 
ves en el diario, hoy, tendrías que ver La Nación, está claro que ya ven la catástrofe que está viniendo, pero en la primera página, ¿qué ponen? El escándalo del concreto chino, y abajo, muy pequeño, que hay una catastrofe natural. ¡No lo ponen! Porque eso te molesta, tú necesitas mostrar que el mercado es bueno y no malo. Y lo del concreto chino se transforma en la única cosa interesante desde semanas. Mientras que en otro país se discute sobre la banca. Aquí por supuesto que no, pues quieren privatizar el banco, eso es bien obvio. Entonces, la economía es eso. Solamente la banca pública, nunca una banca privada, tiene un problema, eso es tan obvio, pero, ¿por qué? Porque eso es una religión, lo privado es lo único racional, que es, a la vez, la única racionalidad, la racionalidad medio-fin. Porque la racionalidad medio-fin opera en el mercado, y este ha sido desarrollado como instrumento de la imposición de la racionalidad medio-fin, es el mercado. Tú tienes todo sobre la racionalidad medio-fin, el mercado y, entonces, la privatización es la universalización de la racionalidad medio-fin, que la racionalidad vida-muerte niega. Hay algo bajo el título bioética, muchas veces bajo el título bioética aparece algo de la racionalidad, pero lo tratan como una cosa especial, aparte y muy curiosa, la bioética "es algo muy curioso y de lo cual hay que hablar", pero nada más. Que la cuestión vida-muerte sea la cuestión no aparece, pero, por lo menos, se nota que hay una gente que se da cuenta de que ocurre eso.

J. J. Bautista: Frente a toda esta catástrofe, que sigue imponiendo el capitalismo hay, más o menos, un sentido común, de que, sí, es evidente que el capitalismo está mal, que está destruyendo todo, pero sigue. Después de todas las críticas que se le han hecho, sigue; pareciera que no hubiese salida, estamos en desacuerdo, pero sigue, y sigue, y sigue desarrollándose. Entonces, usted elabora 
una hipótesis en su obra, que me parece sumamente interesante, en el sentido de que Marx, en El Capital, cuando desarrolla su teoría del valor, no solamente desarrolla la critica a la teoría del valor sino, junto con ello, muestra que, para que funcione la teoría del valor tiene que funcionar, paralelamente, con los valores que producen el capitalismo y la modernidad. Por eso es que, en el fondo, la teoría del valor sería una teoría de los valores.

F. Hinkelammert: De los valores, sin una teoría de los valores no es posible. J. J. Bautista: Exacto, entonces, esto quiere decir que el capitalismo, independientemente de que produzca una economía, produce también una ética, pero no lo presenta como ética. En el caso de Weber, aparece como una racionalidad formal medio-fin y que, en parte, la vez anterior discutíamos cómo, desde Lukács en adelante, habría ingresado al marxismo como un proceso de formalización también del pensamiento material. Entonces, si esto es así, habría una ética implícita en El Capital, en Marx, para cuestionar y criticar esta ética encubierta, con valores, que en apariencia son meramente formales, pero que dominan o encubren, de algún modo, la materialidad de la vida.

F. Hinkelammert: Sí.

J. J. Bautista: ¿Habría esta ética implícita en la obra de Marx, como una crítica a la ética propia del capital o del capitalista?

F. Hinkelammert: Bueno, la cuestión vida-muerte es una ética, una ética de la vida. El capitalismo produce ética, además, necesita ética. Es absurdo decir "nosotros no tenemos ética, nosotros hacemos mercado", pero el mercado es una ética, es la ética de no robar, no engañar, no matar para robar, es una ética, si tú robas te mandan a la cárcel, eso es una ética, pero el capitalismo reduce la ética a este tipo de ley. Por ejemplo, y para tener ejemplos tradicionales, el caso de una deuda, la deuda impagable, lo 
hemos visto ahora muy recientemente, fue el caso muy conocido de Grecia, y ahora Puerto Rico, que tienen el mismo problema, declarada la bancarrota. Pero nadie discute, siquiera, que cuando no se puede pagar no se debe pagar. Ahora tienen que entregar toda Grecia, la han transformado en colonia de Alemania y de la Unión Europea. Prácticamente todos los aeropuertos y puertos son alemanes ahora, porque para pagar la deuda tienen que entregar las propiedades. Entonces, todo lo que era propiedad del Estado pasa ahora a Alemania. El gran músico griego, ese que hizo la entonación del gran poema chileno, él decía: "una cosa está clara: ellos van a pedir privatizar la Acrópolis y se la van a llevar, porque, ¿qué más tenemos para pagar?”. Y ellos cobran y cobran hasta lo último. Y el escándalo es que a Alemania, después de la guerra, le regalaron todo, todas las deudas, casi todo y, además, estaban de acuerdo en no pagar reparaciones de guerra, porque, claro, Alemania no podía pagar. Eso es cierto. Pero le regalaron a Alemania y Alemania con eso logró reestructurarse, pero la razón no era ayudar a Alemania, la razón era ganar la Guerra Fría contrar la Unión Soviética. Nada de bondad. Ahora, ni un peso regalan en Alemania. Ni discuten eso que pasó en 1948-50, se regalaron las deudas a Francia, Inglaterra, Alemania y a todos, excepto a la Unión Soviética, ahí si querían cobrar, y eran mil millones de dólares, que en ese tiempo era mucho. Entonces, ha habido guerra contra la Unión Soviética: que no cumple con sus obligaciones, que no reconoce derechos, etc. Y Alemania, ahora, hace exactamente lo contrario de lo que ha vivido, y en Alemania ni se habla de eso. Bueno, claro, algunos hablan de eso, yo publiqué artículos, uno se publicó en Grecia pero en Alemania... nadie, nadie, nadie. 
J. J. Bautista: Supuestamente, los herederos de la obra de Marx, del pensamiento de Marx, así como escuela, como tradición, fueron los de la primera Escuela de Frankfurt.

Hinkelammert: Sí, sí, sí.

J. J. Bautista: Y después de ello, después de la Segunda Guerra Mundial, se intentó hacer una reconstrucción de esta escuela, a la cual se llamó la segunda generación, y ya vimos los resultados. No diré un desastre, pero no han continuado.

F. Hinkelammert: No, no es continuación.

J. J. Bautista: Cuando abandonan a Marx y optan por Weber y por Kant, ya es otro proyecto completamente distinto.

F. Hinkelammert: Sí, y toda esta ética del diálogo no es continuación de lo anterior, lo han dejado.

J. J. Bautista: Es la gran crisis de todo. Bueno, en parte Dussel y también usted han intentado continuar el proyecto de la teoría crítica, entonces, en opinión suya, ¿qué cosas inconclusas hay todavía y cómo es que se podría continuar? Usted no solamente desarrolla la teoría del fetichismo, sino también la hipótesis de Benjamin, en el sentido de que el capitalismo hay que criticarlo como lo que es, una religión. Entonces, ¿usted diría que esa forma de crítica seguiría siendo algo así como una continuación del proyecto de Marx, o habría otras cosas más que se podrían seguir desarrollando a partir de Marx? Porque, todavía, habría algunas tareas inconclusas o, ¿es que ya podemos empezar a pensar que se puede pensar más allá de Marx, directamente? ¿Cómo vería usted el problema ahora?

F. Hinkelammert: A mí me interesa mucho eso, el capitalismo es religión, ¡es religión! Por eso yo hablé antes de la transformación del mercado en una religión de mercado, que quizás nunca haya sido tan total como con el neoliberalismo. Hay que leer a Hayek para reírse, es absolutamente cómico, es ridículo. Y ahí, la propia crítica de la religión que 
hace falta es la que Marx empezó, de hecho, Marx empezó a criticar el capitalismo como religión, aunque no diga esta misma palabra, pero eso es. Por eso, puedo desarrollar toda la teoría del fetichismo. En el fondo, la teo ría del fetichismo es la teoría de la religión, que es El Capital. Tú lo puedes ver teóricamente, en determinados pasos: plusvalía, ganancia, etcétera, pero, ahora, todo eso hay que verlo desde el punto de vista de que es religión, y eso implica que está muy vinculado con esta cuestión de la ética vida-muerte, es una ética de la muerte que se presenta como vida, y eso es fetichismo, una muerte que se anuncia y se promueve, y se dice que promueve la vida, y eso el capitalismo todo el tiempo lo hace. Ahora Trump ya está bajando los impuestos para el capital.

J. J. Bautista: Para las empresas.

F. Hinkelammert: Del 35 \% al 20\%. ¿Cómo lo justifica? Para ayudar a los obreros y, ¿por qué los ayuda? Si hace eso, los capitalistas van a invertir más, porque tienen más dinero, van a invertir, va a haber más trabajo y, además, al tener más trabajo, van a poder subir los salarios. Eso "no es para capitalistas", es "para obreros". Y eso es así en general, ya con el presidente del Fondo Monetario, Camdessus. ¿Cuál es la manera "más racional" de ayudar a los pobres? Bajar los impuestos de las ricas, porque entonces invierten más, tienen trabajo y los salarios, como concecuencia, van a subir. ¿Qué más podemos hacer para ayudar a los pobres? Eso es lo que tenemos que hacer. ¡Eso es fetichismo! Y hacer ver todos los actos de compra-venta en el sentido de esta relación vida-muerte. Y eso, dentro de la ideología de la burguesía, tiene una tradición, que es ayudar a los pobres, es inclusive hasta quitarles lo que tienen para poder invertir y que después tengan más. Todo esto, ¿qué es? Eso es Camdessus, es grotesco, el realismo del amor al 
prójimo, que es fomentar el mercado neoliberal, donde no se paga nada a nadie excepto a la banca, y eso va a "ser mejor" para ellos.

J. J. Bautista: Lo que se decía en la década del 90: Si quieres optar por el pobre, opta por el Fondo Monetario Internacional.

F. Hinkelammert: ¡Exacto! Y eso fue Camdessus, y la Iglesia Católica lo aceptó, porque cuando él renunció, lo hizo miembro de una institución muy vinculada con el Vaticano, de justicia y paz, y lo nombró miembro de esa institución, como una de las ocho personas que la dirigen, porque "él sabe de justicia y paz", como presidente del Fondo Monetario. Y ahí viene la crítica de la religión, pero como crítica del mercado. El mercado no es eso. Había también esta ideología, esta teoría de que, cuando se bajan los impuestos para los ricos, a los grandes capitales, eso se paga sí mismo, porque va a aumentar la actividad y esta actividad va a pagar impuestos, aunque menos por entidad; pero, como va a haber mucho más, de hecho vamos a tener más ingresos de impuestos de parte de la gran industria sin bajar los impuestos. Son imaginaciones que están por todos lados. Y ahí, siempre está esta figura central de la religión del mercado, que es el propio mercado y el dinero, que se transforma hasta en un objeto de piedad. Goldman y Sacks, este banco mayor, esos son puros religiosos, el jefe dice: "lo que hacemos es obra de Dios", y claro, porque el mercado es Dios, entonces es cierto. Y esta crítica, con Marx, fundada por Marx, también por Feuerbach - pero esta especificidad venía de Marx-, esta enorme crítica de la religión siempre tenía un problema. Después, Marx suponía que, al realizarse el socialismo, la religión iba a morir. Él nunca quiere abolir la religión, quiere abolir el dinero y el Estado; al hacerlo, la consecuencia, sin embargo, va a ser que va a morir la religión, y eso es falso. Esto ha tenido para los países socialistas una 
consecuencia fatal, confundieron crítica de la religión con ateísmo. Entonces, ateísmo significa: ¿existe Dios o no existe Dios? Y si no existe, ¿qué pasa? No pasa nada y, ¿si existe? No pasa gran cosa tampoco. Pero la crítica del fetichismo deja de existir. Que el socialismo se haga ateo es, precisamente, abandonar la crítica de la religión de Marx, a partir de los años 50 del siglo XIX, es crítica del fetichismo, entonces tú no tienes en la tradición del socialismo ni una crítica del fetichismo, casi ninguna. Recientemente me publicaron un libro en Cuba. Ahí sí, en Cuba cambiaron, entonces volvieron a tomar la crítica de la religión y no la cuestión de si Dios existe o no. Marx ni una vez pregunta si Dios existe o no, claro, para él no existe, pero ese no es el problema. Y cuando quieren introducir en el partido social demócrata el ateísmo como condición para ser miembro, él veta eso, tampoco Engels acepta, porque no se trata de ateísmo, se trata de fetichismo. Es decir, si el mercado es Dios, entonces viene el aplastamiento total de la naturaleza y del obrero, lo que Marx ya había dicho en El Capital, pero eso era parte de su crítica de la religión. Ahora, como es un problema de ateísmo, la crítica de la religión de Marx desaparece. Pero ha vuelto, yo creo, yo trato de hacerla volver, pero como crítica del fetichismo, y desarrollar lo que la sociedad puede ser cuando se hace política, una política socialista, etcétera, cuál es el lugar de la religión, que habría que hacer. Pero el lugar de la religión sigue siendo crítica de la religión y, entonces, hay una religión que no es falsa, pero en el sentido de Marx, y eso es otra cosa. Yo me intereso mucho, y lo otro que me interesa es recuperar la teoría del valor-trabajo y la teoría de la plusvalía. Yo encuentro algo fatal que el marxismo haya abandonado estas dos grandes teorías y esté ahora, en vez de eso, con lo que resultó de la crítica de la teoría del valor y la transformación de la teoría del valor-utilidad, que terminó en el 
J. J. Bautista: 
quiere ser científica o filosófica eso no sería lo fundamental, sino que, como el capitalismo es una religión, la crítica pertinente es teológica. Si esto es así, Marx, el Marx maduro, el más duro, habría estado haciendo también teología, no solamente ciencia, no solamente filosofía, sino también, teología. Pero evidentemente lo que decimos, no teología celeste sino teología profana o mundana, secular, pero en perspectiva crítica. $\mathrm{O}$ sea, para hacer la crítica al capitalismo no es suficiente una crítica económica, científica y hasta filosófica, sino también teológica, y esto es algo que no había desarrollado y ni siquiera se le habría ocurrido al marxismo del siglo XX. ¿Cómo lo vería usted?

F. Hinkelammert: Althusser, cuando dice: "antes y lo primero es el Marx filósofo, y después viene el científico”, nunca dice qué ciencia es. Marx hace crítica de la economía política, pero Althusser no ha hecho ninguna cosa en el sentido de una crítica de la economía política, nada. Habla de estructura y, entonces, ¿qué ciencia es eso? Que haga la ciencia que hizo Marx, que es crítica de la economía política y que, en Marx, significa ir más allá de la racionalidad medio-fin a una racionalidad vida-muerte y, a partir de eso, constituir de nuevo la crítica de la economía política, que implica siempre una filosofía y es totalmente cierto. Pero nuestra economía hoy tiene también una filosofía, pero la hacen Heidegger y Wittgenstein, y de una manera tan brutal, que es inaudita. Wittgenstein dice; "yo no veo ninguna diferencia entre el asesinato y la caída de una piedra”. Y le hace a eso un largo análisis. Y esa es la manera científica de ver el mundo, y eso es la f;ilosofía, y ahí hay que recuperar el análisis de Marx pero en el sentido de esta racionalidad, que responda a la irracionalidad de la racionalidad formal. Althusser ni ve eso. Por esto nunca me ha gustado Althusser, no encontré gran cosa detrás de eso. La de eso fue la 
chilena Harnecker, con la cual yo me entendí muy bien, excepto cuando se trató de Althusser. Entonces, se trata de hacer ciencia, pero ciencia no es hacer lo que dice Wittgenstein, es hacer lo que se necesita para entender nuestro mundo. Con Wittgenstein o con Marx, o con quien sea, se trata de entender este mundo, y no de seguir a algún personaje. Y ahí se perdió el marxismo, más bien en un pensamiento de burócratas. que se pueden caer, así como la caída de la Unión Soviética, y esos burócratas se pusieron en el bolsillo todas las propiedad del pueblo, y se transformaron en capital privado. Pero ahí, al terminar la crítica del capitalismo, en este tiempo, en buena parte terminó también el pensamiento del capitalismo, que ya no tenía que contestar a una crítica, y estos pensamientos de Heidegger, Wittgenstein, Max Weber, que estuvieron en esta posición son dominantes, pero para ser científico hay que responder, a la vez, a este tipo de filosofía. Entonces la filosofía no se bota, es absurdo querer botar la filosofía para poder reducir todo al cálculo medio-fin sin justificarlo. Para ellos, la filosofía les pediría justificar la reducción de todo a una racionalidad medio-fin. Pero eso es fatal, eso no se puede, entonces, mejor ni una filosofía, hasta la universidad va a ser sin filosofía, sin historia, también sin psicoanálisis, sin psicología, sin estadística, etc. Esto fue de neoliberales, en cuanto a la universidad, y tú ves esto: la universidad privada no tiene nada más que los elementos necesarios desde el punto de vista del cálculo medio-fin y del mercado, solamente profesiones a favor del mercado, otras no, tú no puedes estudiar en universidades privadas.

J. J. Bautista: Bueno, es más o menos un sentido común para mucha gente que el capitalismo no solo está en crisis, sino que hay una percepción, especialmente en las generaciones jóvenes, de que no solamente estamos anhelando algo 
nuevo, sino que, efectivamente, estamos empezando a ver cómo se podría hacer una transición a lo nuevo. Empezamos a vivir una época de transición, y a esto, desde principios del siglo XXI, con Chávez, se le empezó a llamar primero socialismo del siglo XXI, antes socialismo democrático, en la experiencia boliviana socialismo comunitario, y ya, poco a poco, estamos llegando a la conciencia de que el problema no es tanto el nombre sino qué es aquello que va a ir más allá del capitalismo. Después, poco a poco, lo iremos dotando de contenido. En este proceso de transición, ¿cómo es que deberíamos orientar la acción de tal modo que no recaigamos, por un lado, en el fetichismo y, por otro, en aquello que siempre criticamos en términos de capitalismo y de Modernidad? ¿Cómo lo vería usted? ¿Qué tipo de criterios deberíamos ir desarrollando para hacer efectiva esta transición?

F. Hinkelammert: No es muy fácil, porque las imaginaciones que se produjeron en el siglo XIX, en cuanto al socialismo, hoy no funcionan. Hasta la palabra socialismo, no funciona. Se dice: “iqueremos socialismo!”, pero nadie sabe lo que es eso. Hace 100 años todo mundo sabía, pero ahora no, entonces, "socialismo del siglo XXI"... yo nunca he hablado del socialismo del siglo XXI porque no hay ninguna concepción que diga cuál es. Entonces, hay una base para una nueva sociedad, que primero es negativa. No se puede basar ningún paso al socialismo con la desaparición del mercado, no se puede, ni se puede abolir en Estado, ni el mercado, ni el matrimonio, eso son los tres, se puede cambiar el matrimonio, hacerlo entre hombres o entre mujeres, todo eso, pero no se puede eliminar el matrimonio. ¿No es curioso? ¿Por qué se tienen que casar? Porque el matrimonio es algo "diferente”, es una institución, tú no puedes hacer sociedad sin una institución matrimonio, tú puedes cambiar el 
J. J. Bautista:

F. Hinkelammert: en El Apocalipsis. Eso tenía que venir ya en este tiempo, al final del Apocalipsis viene la "nueva tierra", es la nueva tierra sin matrimonio, sin dinero, sin oro, el oro es para asfaltar la calle, y sin Estado. Han pasado mil años, y se ha leído este Apocalipsis, que hoy es un libro de la derecha, y no se ve que eso es a donde va El Apocalipsis, es comunista. Claro, es algo que "no se puede hacer", Dios lo va hacer, ahí hay una diferencia muy grande, pero cuando yo leí eso de que se va a abolir el dinero y se va asfaltar las calles [con oro] a la gente se les enseña, y dicen: ¡qué maravilloso! No se dan cuenta de que es la abolición del dinero, ni se habla de eso. A Lenin le preguntaron: "¿en el comunismo qué se va a hacer con el oro?" Y entonces dice": "Los urinarios públicos”. Es lo mismo que dice El Apocalipsis, porque la calle, en este tiempo, son urinarios, y la gente que lee El Apocalipsis por supuesto no se da cuenta, orinan encima, y Lenin se dio cuenta ¡Quizá es de lo único de lo que se ha dado cuenta! Y eso es también El Apocalipsis.

J. J. Bautista: Entonces, ¿cómo sintetizaría usted ese criterio de posibilidad? Digamos ese criterio de orientación, ese criterio de posibilidad para una transición?

F. Hinkelammert: Un mercado sistemáticamente intervenido, desde el punto de vista de no destruir la naturaleza, no destruir al ser humano y marginar el negocio de la banca. Esos son los tres, pero eso es de Marx. Pensar una nueva sociedad... yo creo que eso es quizás un poco... demasiado secular, pero yo no podría decir otra cosa, y en estos términos significa una convivencia completamente diferente, pero a partir de mercado-Estado-matrimonio. 
Esta idea de El Apocalipsis, que aparece después en el anarquismo y de alguna manera está en el comunismo de Marx, es algo maravilloso, como una ausencia que está presente y no algo por hacer. A mí me ha impresionado mucho este paso de El Apocalipsis al comunismo y la antiautoridad, y es realmente algo que hay que tomar. En las grandes religiones se hacen reflexiones de este tipo, que hoy tú no puedes hacer religiosamente, porque lo pones en lo profano, pero hay una continuidad.

J. J. Bautista: Bueno, Franz, estas habrían sido las preguntas, le agradecemos mucho por el tiempo, ¡la paciencia!

F. Hinkelammert: No, ;fue muy bueno, muy bueno! 